\title{
TEMAS CENTRALES EN LOS DEBATES LEGISLATIVOS SOBRE LA «DESLAICIZACIÓN» DE LA EDUCACIÓN LAICA EN MÉXICO (1992-1993)
}

\section{Central Subjects in Legislative Debates on the "Deslaicization" of Laic Education in México (1992-1993)}

\section{Adelina Arredondo ${ }^{\&}$ y Alejandro Ortiz Cirilo ${ }^{\beta}$}

Fecha de recepción: 17/12/2017 • Fecha de aceptación: 12/05/2018

Resumen. Como parte del proyecto de modernización del Estado, del restablecimiento de las relaciones diplomáticas con El Vaticano y la reconfiguración de las relaciones entre el gobierno y la Iglesia católica en México, en 1992 el presidente Carlos Salinas de Gortari presentó ante el Congreso de la Unión un proyecto de reforma constitucional en materia educativa que permitió la impartición de enseñanza religiosa en las escuelas privadas, prohibida desde 1917. Fue así como se redujo el régimen de laicidad educativa, por lo que significó un proceso de «deslaicización». Nuestro propósito en este artículo es analizar los núcleos de las discusiones parlamentarias relativas a la educación laica en México durante la LV Legislatura (1991-1994). El objetivo central es examinar cuáles fueron los cambios en relación al régimen educativo establecido desde 1917. Nos interesa esclarecer cuáles fueron sus antecedentes, indagar los puntos principales de la iniciativa presidencial, el procedimiento legislativo que se siguió desde que se presentó la propuesta de reforma constitucional hasta su entrada en vigor. Finalmente, identificamos las posiciones, los argumentos, los temas, las propuestas que se enfrentaron en los debates parlamentarios, las negociaciones y los acuerdos a los que se llegaron para lograr concretar la reforma constitucional al artículo 3.

Palabras clave: Educación laica; Reformas educativas; Educación religiosa; Estado e Iglesia; México.

\footnotetext{
\& Instituto de Ciencias de la Educación. Universidad Autónoma del Estado de Morelos. Av. Universidad. 1001, Colonia Chamilpa, Cuernavaca, Morelos, México.62209. adelinaarredondo@yahoo.com

${ }^{B}$ Instituto de Ciencias de la Educación. Universidad Autónoma del Estado de Morelos. Av. Universidad.1001, Colonia Chamilpa, Cuernavaca, Morelos, México.62209. aortizc1985@gmail.com
}

Cómo citar este artículo: Arredondo, Adelina y Alejandro Ortiz Cirilo. «Temas centrales en los debates legislativos sobre la "deslaicización" de la educación laica en México (1992-1993)». Historia y Memoria de la Educación 9 (2019): 343-377. 
Abstract. As part of a project to modernize the State, the reestablishment of diplomatic relations with The Vatican and the reconfiguration of the relationship between the government and the Catholic Church in Mexico, in 1992 president Carlos Salinas de Gortari presented at the National Congress a constitutional reform project in educational policy. This reform allowed religious teaching in private schools, which had been banned since 1917. In this way the regime of educational laicism was reduced, this being the reason why we call it a process of "de-laicization». Our purpose here is to analyze the core of the discussions in parliamentary debates regarding the transformation of the regimen of secular (lay) education in Mexico during the LV Legislature (1991-1994). The main objective is to examine the changes in relation to the national education system established in the Constitution of 1917. We are interested in clarifying its antecedents, investigating the main points of the presidential project and the legislative procedure that was followed from the time the proposal of the constitutional reform was presented until it came into effect. Finally, we identify the positions, arguments, themes, and proposals that were addressed in Parliament as well as the negotiations and the agreements reached in order to achieve the constitutional reform of the $3^{\text {rd }}$ article of the Constitution in the subject of secular education.

Keywords: Laic Education; Educational Reforms; Religious Education; Church and State; Mexico.

\section{INTRODUCCIÓN}

En este artículo analizamos los debates legislativos respecto a la educación laica en México durante el Congreso de la Unión durante la LV legislatura (1991-1994). En el desarrollo del escrito se enuncian los puntos principales de la iniciativa de reforma propuesta por Carlos Salinas de Gortari y se identifican las posiciones que se enfrentaron, los argumentos, negociaciones y acuerdos tomados para reformar el artículo 3 constitucional que regula la educación. De forma excepcional, en el transcurso de un periodo legislativo y en poco más de un año ese artículo se reformó en dos ocasiones.

El procedimiento para realizar este trabajo consistió en la revisión de los diarios de los debates parlamentarios que se suscitaron durante la LV legislatura (1991-1994). Esa revisión fue muy importante porque a través de ella se pueden apreciar con mayor claridad los intereses en juego; asimismo, se pueden ubicar diversos puntos de vista e incluso las 
alianzas, coaliciones y puntos de acuerdo entre legisladores. También se consultaron folletos, actas de sesiones, periódicos, notas de opinión y libros.

Uno de los problemas en esta investigación consistió en ubicar los temas subyacentes al carácter laico de la educación qué, más allá de su definición conceptual, comprendió distintos elementos que van desde la formulación de los contenidos en los planes y programas de estudio y el campo de su aplicación, hasta las restricciones de quiénes pueden o no participar en los procesos educativos formales. Para el caso de las reformas en torno a la laicidad educativa, las posiciones que se manifestaron en el Congreso representaron posturas que van desde las tradiciones liberales que han configurado el constitucionalismo mexicano desde mediados del siglo XIX y xx, hasta los intereses de los grupos conservadores que buscan fortalecer el posicionamiento político y un tratamiento legal especial para la Iglesia Católica.

\section{ANTECEDENTES}

La Nueva España (actualmente Estados Unidos Mexicanos) obtuvo la independencia política de España en 1821. Desde su inicio la expansión de la instrucción pública fue uno de los objetivos gubernamentales. A través de los distintos ordenamientos federales y centralistas se estableció la universalidad de la instrucción primaria, que debía ser pública, gratuita y obligatoria. ${ }^{1} \mathrm{~A}$ estos principios se sumó pronto un principio más: ser laica. El 15 de abril de 1861 se expidió el «Decreto de gobierno sobre arreglo de la instrucción Pública». ${ }^{2}$ Esta ley reglamentó el currículum escolar omitiendo los contenidos religiosos, que habían sido uno de los ejes formativos hasta esa fecha. Siendo la república de carácter federal, el decreto tuvo vigencia en el Distrito Federal y territorios federales, pero cada entidad fue reglamentando la educa-

\footnotetext{
${ }^{1}$ Anne Staples, Educar: panacea del México independiente (México: Ediciones el caballito, 1985); Adelina Arredondo. «De la educación religiosa a la educación laica en el currículum oficial de instrucción primaria en México (1821-1917)», Espacio, Tiempo y Educación 4, no. 2 (2017): 1-x. doi: http://dx.doi.org/10.14516/ete.192

${ }^{2}$ Manuel Dublán y José María Lozano, «Decreto del gobierno para el arreglo de la instrucción pública en el Distrito Federal y territorios federales», Legislación mexicana ó colección completa de las disposiciones legislativas (1861), tomo IX, 150.
} 
ción pública en el mismo sentido. Primero se omitieron los contenidos religiosos del currículum y más tarde se fue prohibiendo la participación de los ministros de culto en la educación. ${ }^{3}$ La educación laica estaba presente primero prescindiendo de los contenidos religiosos, y después prohibiendo toda enseñanza religiosa en los establecimientos oficiales. El 25 de septiembre de 1873, el presidente Sebastián Lerdo de Tejada, promulgó un decreto que incorporó las leyes de reforma a la Constitución de 1857; en estas leyes se estableció la independencia entre el Estado y la Iglesia, el matrimonio civil y la prohibición de establecer órdenes monásticas. ${ }^{4}$

En 1890 el Congreso de la Unión facultó al presidente de la república para organizar y reglamentar la instrucción primaria en el Distrito Federal y territorios de Tepic y Baja California. El artículo 2 de esta ley reglamentaria estableció que «La enseñanza obligatoria que se imparta en las escuelas oficiales será, además, gratuita y laica». ${ }^{5}$ Estos cambios fueron un punto de referencia importante en los debates posteriores que se suscitaron en el constituyente de 1917, que en su artículo 3 estableció la educación laica en todo el país en todos los establecimientos oficiales y en establecimientos particulares de educación primaria. Al mismo tiempo reiteró la prohibición de que las corporaciones religiosas y ministros de culto intervinieran en la educación elemental, como educadores, administradores e incluso financiadores. ${ }^{6}$ Los ideólogos de la Revolución consideraron que ésta era la mejor fórmula para asegurar la libertad de creencias, generalizando la laicidad educativa para afirmar la igualdad de oportunidades para todos los educandos de cualquier

\footnotetext{
${ }^{3}$ Roberto González Villarreal y Adelina Arredondo, «1861: la emergencia de la educación laica en México», Historia Caribe XII, no. 30 (2017): 25-49. http://dx.doi.org/10.15648/hc.30.2016.2 Para un análisis más amplio de la historia de la educación laica en México véase, Adelina Arredondo y Roberto González, «De la secularización a la laicidad educativa en México», Historia de la Educación. Anuario. Publicación de la Sociedad Argentina de Historia de la Educación 15, no. 2 (2014): 140-167.

${ }^{4}$ Manuel Dublán y José María Lozano (comps.), Legislación mexicana o colección completa de las disposiciones legislativas expedidas desde la Independencia de la República (México: Imprenta del Comercio de E. Dublán y Comp., 1882) tomo XII, 502.

${ }^{5}$ Nicolás Islas y Bustamante, Colección de Leyes, Decretos, Reglamentos y Disposiciones sobre Instrucción Pública Vigentes en el Distrito Federal y Territorios de Tepic y Baja California (México: El libro diario, 1893), 21.

${ }^{6}$ Diario Oficial de la Federación, «Constitución Política de los Estados Unidos Mexicanos» V, no. 4 (5 de febrero de 1917): 149. http://www.diputados.gob.mx/LeyesBiblio/ref/cpeum/CPEUM_orig_ 05feb1917.pdf (consultado el 20-10-2017).
} 
credo; con ello minaban el poder de los grupos conservadores aliados a la iglesia católica y garantizaban el control político.

Las políticas educativas y en particular el artículo 3 de la Constitución de 1917 que prohibía la enseñanza religiosa, no sólo en escuelas estatales sino también particulares, tuvieron la oposición de la Iglesia católica de manera directa o a través de organizaciones como la Unión Nacional de Padres de Familia (UNPF), que se presentaba como una organización secular a favor de la libertad de enseñanza. No obstante, desde sus inicios estuvo vinculada a la Iglesia católica y tenía como uno de sus objetivos derogar las disposiciones del artículo 3 que regulaba la laicidad en las escuelas privadas. La UNPF declaró que «la educación de los hijos no era función del Estado, sino que es un derecho y un deber de los padres de familia». ${ }^{7}$ Además, afirmó que defendería los colegios particulares, recuperaría la influencia de la Iglesia en el terreno educativo, y se autoproclamaba como reivindicadora de la libertad de enseñanza, entendida como la libertad de enseñar religión. ${ }^{8}$ En sus estatutos generales la Unión Nacional de Padres de Familia fijó como un objetivo "proteger y hacer que se respetase la familia como base indispensable de la convivencia social y que se garantizasen los elementos morales, económicos y sociales para cumplir esta misión». ${ }^{9}$ Estas demandas serían retomadas posteriormente en las discusiones parlamentarias de la LV legislatura, en 1992.

Posteriormente el artículo 3 constitucional pasó por dos reformas importantes, una en 1934 y otra en $1946 .{ }^{10}$ La primera declaró el carácter socialista de la educación pública, decretando la enseñanza racional. ${ }^{11}$ La segunda omitió el carácter socialista establecido con anterioridad, pero amplió el carácter laico a todas las instituciones estatales de

\footnotetext{
${ }^{7}$ Boletín de la Unión Nacional de Padres de Familia, 7, 2. ${ }^{a}$ época, febrero y marzo de 1961, México.

${ }^{8}$ Marco Aurelio Pérez Méndez, «La Unión Nacional de Padres de Familia y la oposición a la política educativa del Estado revolucionario: 1917-1940», en Representaciones y prácticas sociales. Visiones desde la historia moderna y contemporánea, ed. Rodrigo Laguarda (Cuadernos de Trabajo de posgrado. Historia Moderna y Contemporánea. Maestría, México, Instituto Mora, 2013), 131-165.

${ }_{9}$ Unión Nacional de Padres de Familia, Estatutos generales (México: UNPF, 1963), 2.

${ }^{10}$ Diario Oficial de la Federación, «Decreto que reforma el artículo 3 y la fracción XXV del 73 constitucionales» LXXXVII, no. 85 (13 de diciembre de 1934): 849-851. http://www.diputados.gob.mx/ LeyesBiblio/ref/dof/CPEUM_ref_020_13dic34_ima.pdf (consultado el 20-10-2017).

${ }^{11}$ Alberto Bremauntz, La educación socialista en México (antecedentes y fundamento de la reforma de 1934) (México: Rivadeneira, 1943).
} 
cualquier nivel; también incluyó las escuelas privadas de nivel primaria, secundaria y normal, y la capacitación de obreros y campesinos. ${ }^{12}$ Las escuelas particulares, continuaron obligadas a seguir los planes y programas oficiales, laicos. La Fracción IV del artículo 3 amplió las restricciones para prohibir que las corporaciones religiosas y los ministros de culto intervinieran en actividades educativas.

En la legislación mexicana, donde el respeto a la libertad de creencias ha sido y es un artículo fundamental, no se negaba el derecho a la educación religiosa. Sólo se suponía que este tipo de enseñanza pertenecía al terreno privado y correspondía a los padres de familia o a las iglesias otorgarla. Se consideraba que incluso las escuelas particulares eran entidades públicas donde nadie tenía el derecho de imponer sus convicciones religiosas y era una tarea del gobierno garantizar esa libertad. Así pues, el régimen laico como forma de gobierno de la educación estuvo presente en la educación pública durante 131 años, ampliándose también a las escuelas privadas durante 75 años. Sin embargo, las últimas dos reformas constitucionales que se promulgaron durante la gestión presidencial de Carlos Salinas de Gortari, en 1992 y 1993, modificaron este régimen educativo. En esta ocasión, las reformas tomaron un nuevo rumbo, y la educación se orientó por una lógica de mercado. ${ }^{13} \mathrm{El}$ ámbito educativo se mostró propicio para ofrecer nuevos espacios de participación, y permitir una mayor intervención de distintos sectores de la sociedad, entre los que también se encontraban grupos empresariales religiosos, sobre todo grupos ligados a la Iglesia católica. ${ }^{14}$ Los cambios que se impulsaron desde el Congreso de la Unión no fueron menores porque se creó una división en el sistema educativo mexicano. A raíz de estas reformas constitucionales, es posible ubicar un modelo de escuela pública laica y una escuela privada con la posibilidad de adquirir una orientación abiertamente confesional.

12 Diario Oficial de la Federación, «Decreto que reforma el artículo 3 de la Constitución Política de los Estados Unidos Mexicanos», 30 de diciembre de 1946. http://www.diputados.gob.mx/ LeyesBiblio/ref/dof/CPEUM_ref_041_30dic46_ima.pdf (consultado el 20-10-2017)

${ }^{13}$ Alejandra Jablonska, «Modernización educativa y ética de la productividad: ejes del nuevo modelo de desarrollo», Revista Mexicana de Ciencias Políticas y Sociales 39, no. 157 (1994): 91-111.

${ }^{14}$ Aurora Loyo (coord.), Los actores sociales y la educación: los sentidos del cambio (1988-1994) (México: Instituto de Investigaciones Sociales/Plaza y Valdés Editores, 1997). 
Después de una gradual expansión del espacio de laicidad, que comenzó en el siglo xIX con la expedición de leyes reglamentarias que omitieron los contenidos religiosos, y que siguió durante todo el siglo xx, con la promulgación de la Constitución de 1917 y sus posteriores reformas en 1934 y 1946 ¿Es posible observar un proceso de deslaicización en el sistema educativo mexicano? En todo caso ¿cuáles fueron las condiciones al interior del Congreso que permitieron llevar a cabo estas reformas constitucionales en el artículo 3?, Y sobre todo, ¿cuáles fueron los argumentos que se esgrimieron en los debates parlamentarios para impulsar estas reformas?, ¿cuáles fueron los puntos principales de la iniciativa presidencial?, ¿cuáles fueron los cambios en relación al régimen educativo de 1946? ¿quiénes fueron los promotores de dichas enmiendas?, ¿cuáles fueron los temas discutidos? ¿a qué acuerdos se llegaron?, ¿qué perspectivas políticas fueron las que se impusieron?

En los siguientes capítulos explicaremos cuál fue la coyuntura política que propició la reforma del régimen de laicidad educativo, en qué consistió la iniciativa del presidente a las cámaras, qué seguimiento tuvo, qué posiciones partidistas se manifestaron, cuáles fueron las fuerzas que debatieron ese punto en el parlamento y con qué argumentos, centrándonos sobre todo en la identificación y el análisis de los núcleos de discusión.

\section{LAS RELACIONES ESTADO-IGLESIA COMO PARTE DEL CONTEXTO POLÍTICO DE LA REFORMA AL ARTÍCULO 3 CONSTITUCIONAL}

Desde su campaña presidencial, Carlos Salinas consideró que el tema de la educación era relevante dentro de su proyecto de modernización, asunto al que le dedicó una mención especial en la mayor parte de sus actos políticos. Desde su perspectiva, la educación era un medio para generar nuevas actitudes y propiciar mentalidades informadas y comprometidas con los valores de la mexicanidad. ${ }^{15}$

${ }^{15}$ Carlos Salinas de Gortari, «Diálogo Nacional», Revista de la consulta popular, Educación (México: Partido Revolucionario Institucional, Instituto de Estudios Políticos, Económicos y Sociales, 1987), 9. 
La reforma del artículo 3 era vista por el gobierno en turno como una estrategia para promover una imagen de modernidad, sobre todo hacía el ámbito internacional, en la medida en que se regresaba al concepto de libertad educativa y con ello se pretendía el respeto a la diversidad. Los cambios a la Constitución en materia religiosa y educativa fueron decisión del presidente Salinas, derivados de un proyecto modernizador, neoliberal, que se impulsó a lo largo de toda su gestión presidencial. Las reformas propuestas por el presidente estuvieron apoyadas por los legisladores del PRI, del PAN y miembros de la jerarquía católica.

En su discurso de toma de posesión presidencial se manifestó un acercamiento directo con líderes de la jerarquía católica. El proyecto de modernización contempló cambios en el esquema de la relación Estado-Iglesia, ya que desde su punto de vista, «El Estado moderno es aquel que [...] mantiene transparencia y moderniza su relación con los partidos políticos, con los sindicatos, con los grupos empresariales, con la Iglesia, con las nuevas organizaciones en el campo y en las ciudades» ${ }^{16}$ La mención de la Iglesia en un discursos político, presidencial, era una novedad; las generaciones presentes no habían presenciado que se mencionara a la Iglesia en un discurso político presidencial como interlocutora del Estado. Esto no había ocurrido durante las trece décadas anteriores.

Un hecho inusitado en este evento fue la asistencia de miembros de la jerarquía católica, pues de acuerdo al carácter laico del Estado mexicano, se había mantenido no sólo una neutralidad con respecto a los representantes de organizaciones religiosas, sino que se les mantenía ajenos a toda participación política. Destacaron en ese acto el cardenal Ernesto Corripio Ahumada, Arzobispo Primado de México; Girolamo Prigione, delegado apostólico en México; Adolfo Suarez Rivera, presidente de la Conferencia Episcopal; Juan Jesús Posadas Ocampo, secretario de la conferencia Episcopal, y Manuel Pérez Gil, obispo de Tlalnepantla, una de las diócesis más populosas.

\footnotetext{
${ }^{16}$ Carlos Salinas de Gortari, «Discurso de toma de posesión como presidente constitucional de los Estados Unidos Mexicanos», México, Congreso de la Unión, 1. ${ }^{\circ}$ de diciembre de 1988. http://www. biblioteca.tv/artman2/publish/1988_67/Discurso_de_Toma_de_Posesi_n_de_Carlos_Salinas_de_74. shtml (consultado el 24-4-2018).
} 
El acercamiento entre la jerarquía católica con el presidente Salinas llegó a tal punto que, incluso, el 5 de junio de 1989 el Episcopado Mexicano le entregó una serie de propuestas para reformar los artículos 3, 5, 27 y 130 de la Constitución, ya que consideraban que estos artículos «no tuvieron, ni tienen en la actualidad legitimidad substancial en los términos que se han expuesto. Esta circunstancia se revela en su permanente inaplicabilidad y por ende en su insolvencia real. ${ }^{17}$ En cuanto al artículo 3, la propuesta del episcopado contemplaba la desaparición de las fracciones III, IV, V y VII, en las que se prohibía la intervención de las corporaciones religiosas y ministros de culto en los planteles en los que se imparta educación primaria, secundaria y normal, y la destinada a obreros y campesinos. Su propuesta sugiere también suprimir la capacidad jurídica del Estado para retirar discrecionalmente, en cualquier tiempo, el reconocimiento de validez oficial a los estudios hechos en planteles particulares. Sólo aceptaba conservar la obligatoriedad de la educación primaria.

A lo largo de toda la gestión presidencial salinista se introdujo una serie de reformas a la Constitución Política de los Estados Unidos Mexicanos y a las formas de relación entre los gobernantes y otros actores sociales. Se signaron pactos y tratados internacionales como el Tratado de Libre Comercio con Estados Unidos y Canadá, se reprivatizó la banca, se negoció la deuda externa y, en general, se contempló la integración de grupos empresariales en la política oficial. ${ }^{18}$ Este tipo de acciones tuvieron un impacto considerable en la política educativa, pues dicho proceso de modernización no se podía entender sin tomar en cuenta la educación básica.

Como consecuencia de esta apertura, la Iglesia católica intensificó su participación política a lo largo de los años noventa. Su acción se desplegó a través de tres distintas facciones que se complementaron para demandar que se reformara el marco jurídico que limitaba su participación en la sociedad mexicana. El primer grupo identificado por Carlos Fazio como «jurídico-triunfalista», partía del concepto de Igle-

\footnotetext{
${ }^{17}$ Ramón Sánchez Medal, La presencia de Juan Pablo II en México y las relaciones Iglesia-Estado (México: Grupo Promoval, 1992), XII-XIV.

${ }^{18}$ Carlos Elizondo Mayer-Serra, «El Estado mexicano después de su reforma», Política y gobierno II, no. 1 (1995): 95-113.
} 
sia/sociedad perfecta y reclamaba derechos e instrumentos para llevar a cabo su labor, ésta corriente aparentemente no estaba muy interesada en la reforma de la Constitución y sostenía que los verdaderos profetas no necesitaban leyes para actuar. Así lo expresó Samuel Ruíz «No necesitamos cambios de legislación cuando queremos realmente defender al pueblo». Por otra parte, se encontraba el grupo más conservador, ideológicamente "neopanista», al que se le habían identificado nexos con grupos empresariales radicales como Pro-Vida, la COPARMEX y la CONCANACO. Su discurso llegó a ser abiertamente contestatario y beligerante respecto al gobierno. ${ }^{19}$ La tercera corriente era la mayoritaria a la que Fazio denomina "pragmático-diplomática». Ésta aceptaba el reconocimiento de la autoridad existente y estaba liderada por Girolamo Prigione; las tres corrientes eran muy activas políticamente.

Cuando comenzó el acercamiento entre líderes de la jerarquía católica y funcionarios públicos para discutir el tema de las relaciones Estado-Iglesia, algunos miembros de la jerarquía católica celebraron que se comenzara el diálogo sobre este asunto. Sergio Obeso, presidente de la Conferencia Episcopal Mexicana, afirmó que se acabaría la semiclandestinidad porque se había comenzado con el diálogo nacional sobre cosas que de una u otra manera parecían intocables y sacralizadas en una ley fosilizada que estaba vigente pero que no se aplicaba. ${ }^{20}$

El 1. ${ }^{\circ}$ de noviembre de 1991 durante su tercer informe de gobierno, el presidente Carlos Salinas de Gortari acotó que en México la situación jurídica de las iglesias derivó de razones políticas y económicas en la historia y no en disputas doctrinarias sobre las creencias religiosas. Desde su punto de vista, la solución a conflictos del pasado consistía en promover una nueva situación jurídica de las iglesias, respetar la libertad de creencias de cada mexicano y manteniendo la educación laica en las escuelas públicas. ${ }^{21}$ En otras palabras, el presidente Salinas estaba proponiendo un cambio en el régimen de laicidad educativa. El cambio propuesto por el presidente sólo contemplaba que la educación pública

\footnotetext{
${ }^{19}$ Carlos Fazio, Samuel Ruíz. El caminante (México: Espasa Calpe, 1994), 199.

${ }^{20}$ Manuel Olimón Nolasco, «Entrevista con Monseñor Sergio Obeso», Excélsior (México), 7 de febrero de 1989.

${ }^{21}$ Cámara de Diputados, Informes presidenciales. Carlos Salinas de Gortari (México: Dirección de Servicios de Investigación y Análisis, Subdirección de Referencia Especializada, 2006), 182-183.
} 
fuera laica, permitiendo así que las escuelas privadas pudieran impartir clases de religión, en particular de doctrina católica.

Aunque la Constitución establecía restricciones a la participación de las instituciones religiosas en la educación, en la práctica la Iglesia católica estaba bajo un régimen de excepción pues se soslayaba que en ocasiones las escuelas particulares impartían contenidos adicionales con orientaciones religiosas. Cabe aclarar que México es una república federal, integrada por 32 entidades federativas que se llaman estados. La educación está controlada por un Estado federal «nacional», pero las entidades federativas «estados» administran y financian sus propias escuelas. Por lo tanto, se puede hablar de un sistema educativo en tres subsistemas escolares, el de la federación, el de los estados o entidades federativas y el de las escuelas particulares. De acuerdo con Torres Septién, en términos legales, la educación particular en México debía ajustarse a las disposiciones oficiales; sin embargo, en los hechos, había matices diferenciados entre la escuela pública y la privada; uno de los principales era que en la escuela privada había la posibilidad de impartir una serie de enseñanza adicionales con enfoques muy específicos de índole religiosa, no obstante a estar prohibido por el artículo tercero y las leyes educativas desde 1917.22

Por su parte, Pedro Castro señala que la Iglesia católica ejercía actividades en el campo de la educación sin mayores contratiempos, y hasta los años sesenta centró sus esfuerzos en la educación privada, donde cumplió con amplitud su papel de agente cultural. Este tipo de educación privada estaba dirigido principalmente a las clases medias y altas, es decir, a quienes podían pagar los servicios de las escuelas particulares. Según afirma Castro, «de este reducido núcleo no tardarían en aparecer líderes políticos o de la empresa privada, e incluso profesionales libres y empleados que engrosaban las filas de la militancia católica». Y según el mismo autor:

Hacia 1979, el Arzobispado mexicano ofrece una idea aproximada de la fuerza de la Iglesia en el ramo de la educación: para este año, la Iglesia había logrado contar con 361 jardines

\footnotetext{
${ }_{22}$ Valentina Torres Septién, La educación privada en México 1903-1976 (México: El Colegio de México/Universidad Iberoamericana, 1997), 18.
} 
de niños; 15552 escuelas primarias con cerca de 600 mil alumnos; 952 escuelas de educación media con casi 250 mil alumnos y 60 mil estudiantes en universidades e institutos de enseñanza superior. $^{23}$

Por otra parte, uno de los cambios más importantes durante este periodo fue el crecimiento exponencial de la demanda educativa. Sin duda, esto preocupó a distintos sectores de la población. La Unión Nacional de Padres de Familia, por su parte, señalaba que:

En 1970 la matrícula de primaria a nivel nacional fue de 9 millones 284 mil educandos, para satisfacer esta matricula tanto el Estado como la sociedad se encontraban involucrados de la siguiente forma, las escuelas federales representaban el $65.7 \%$ de la matricula señalada; las escuelas estatales el $26.5 \%$ y las escuelas particulares el 7.8\%. La situación cambió 20 años después. La matrícula de primaria en 1990 fue de 14 millones 622 mil educandos, las escuelas federales representaban ahora el $72 \%$ de esa matricula, en cambio las escuelas estatales disminuyeron al $22.4 \%$ y las particulares al $5.7 \% .{ }^{24}$

Estas estimaciones reflejan un incremento de más de 5 millones de educandos, en un periodo que fue relativamente corto. También se puede observar que las escuelas a cargo del Estado incrementan su matrícula escolar, mientras que las estatales y sobre todo las particulares decrecieron en la atención a la demanda. Por esta razón la Unión Nacional de Padres de Familia estaba a favor de la reforma educativa, pues consideraban que, por un lado, se garantizaban los derechos humanos de los niños al recibir el tipo de educación de acuerdo con sus convicciones éticas y morales y, por otro lado, se cubría la demanda cada vez mayor de educación básica en la población mexicana, lo que a la vez aligeraba la carga financiera del Estado.

\footnotetext{
${ }^{23}$ Pedro Castro, «Iglesia y Estado en México: la era de las afinidades», en Las políticas salinistas: balance a mitad de sexenio (1988-1991), coord. Pedro Castro (México: Universidad Autónoma Metropolitana, Unidad Iztapalapa, 1993), 121.

${ }^{24}$ Unión Nacional de Padres de Familia, «Análisis de la iniciativa de reformas a los artículos tercero y 31 de la Constitución Política de los Estados Unidos Mexicano», en Honorable Congreso de la Unión, Información sobre el artículo 3 constitucional, Cuadernos de Apoyo 11 (1992), 4.
} 
Así, el argumento del sector privado era que el Estado no estaba absorbiendo la demanda educativa con suficiente velocidad ni con la calidad que la época de globalización exigía, y que el sector privado podría contribuir a ello si tuviera condiciones más favorables. De hecho, los servicios educativos, los de salud, transporte, comunicaciones, vivienda, así como otros sectores productivos como el energético y el financiero, eran reclamados por los inversionistas privados en el marco del libre comercio y las inversiones extranjeras, espacios que antes estaban reservados al sector público. Por lo que respecta al sector educativo privado, en la actualidad representa el $16.8 \%$ de la cobertura total, cuando en 1990 era de $5.7 \% .^{25}$

Además de ocuparse de la cobertura educativa, el gobierno federal impulsó el Programa de Modernización Educativa. La novedad en dicho programa consistió en involucrar en el proceso de enseñanza-aprendizaje a los padres de familia, maestros y otros grupos sociales, entre los que también se encontraba la Iglesia, a través de la formación de Consejos de Participación Social. ${ }^{26}$ Desde el programa propuesto por el presidente Salinas se contempló que la Iglesia católica pudiera involucrarse cada vez más en la educación y sobre todo reconocer, reglamentar y controlar su actividad en la instrucción privada.

Las intenciones expresadas desde su campaña presidencial, en su discurso de toma de posesión y en su ercer informe de gobierno, se plasmaron finalmente en una iniciativa de reforma al artículo tercero constitucional.

\footnotetext{
${ }^{25}$ Secretaría de Educación Pública, «Estadísticas del Sistema Educativo», México. Ciclo Escolar 2016-2017. http://snie.sep.gob.mx/descargas/estadistica_e_indicadores/estadistica_e_indicadores_educativos_33Nacional.pdf (consultado el 24-4-2018) Una visión retrospectiva y muy actual del fenómeno de privatización educativa y del sustrato laboral y financiero que subyacía en esas y las reformas neoliberales subsecuentes, puede encontrarse en el libro de Roberto González, Lucía Rivera y Marcelino Guerra, Anatomía política de la reforma educativa (México: UPN, 2017), disponible en http://editorial.upnvirtual.edu.mx/index.php/9-publicaciones-upn/379-anatomia-politica-dela-reforma-educativa (consultado el 24-4-2018).

${ }^{26}$ Josefina Zoraida Vázquez, «La modernización educativa (1988-1994)», Historia Mexicana XLVI, no. 4 (1996): 927-952.
} 


\section{EL ESCENARIO POLÍTICO DE LAS DISCUSIONES PARLAMENTARIAS}

Durante la LV legislatura (1991-1994), se realizaron reformas constitucionales en las siguiente materias: agraria, administración pública, derechos humanos, económica, electoral federal, financiera, fiscal, gobierno interior del congreso, justicia, monetaria, relaciones internacionales, responsabilidad de servidores públicos, seguridad social, educación y relaciones Estado-Iglesia. ${ }^{27}$

Una característica notable en esta legislatura fue el predominio de legisladores afiliados al Partido Revolucionario Institucional (PRI) de corte centralista, que se había mantenido en el poder desde hacía siete décadas; sin embargo, la alianza de otros partidos políticos fue fundamental para lograr acuerdos que permitieran reformar la constitución, como fue el caso del Partido Acción Nacional (PAN) ubicado en el espacio de centro-derecha, que desde sus orígenes estuvo ligado a grupos empresariales, y durante este periodo sostuvo una relación estrecha con el presidente de la República en una negociación constante y se constituyó como una oposición leal al régimen autoritario. ${ }^{28}$ Por su parte, el Partido de la Revolución Democrática (PRD), que se ha definido como un partido de centro-izquierda, durante esta legislatura, en particular, se mantuvo como una fuerza política que se opuso a las propuestas de reformas constitucionales enviadas por el presidente Salinas. ${ }^{29}$ Puntos de vista divergentes apuntaban que la democracia mexicana se había vuelto competitiva por la creación e impulso de partidos «menores» como lo fueron en su momento el Partido Popular Socialista (PPS), que fue resultado de la separación de la Confederación de Trabajadores Mexicanos (CTM) del PRI, ${ }^{30}$ el Partido del Frente Cardenista de Reconstrucción Nacional (PFCRN) que pretendía establecer una alianza con

\footnotetext{
${ }^{27}$ Honorable Cámara de Diputados, LV legislatura, Breviario de la Quincuagésima Quinta Legislatura de la Cámara de Diputados del H. Congreso de la Unión 1991-1994, julio de 1994.

${ }^{28}$ Soledad Loaeza, El Partido Acción Nacional: la larga marcha, 1939-1994 oposición leal y partido de protesta (México: Fondo de Cultura Económica, 1999), 478.

29 Jorge Cadena-Roa y Miguel Armando López Leyva (comps.), El PRD: orígenes, itinerarios, retos (México: Universidad Nacional Autónoma de México/Instituto de Investigaciones Sociales/Centro de investigaciones Interdisciplinarias en Ciencias y Humanidades, 2013).

${ }^{30}$ Antonio Delhumeau, México: realidad política de sus partidos (México: Instituto Mexicano de Estudios Políticos A.C., 1977).
} 
los sectores obreros y campesinos, y, por último el Partido Auténtico de la Revolución Mexicana (PARM), que se originó luego de haberse suprimido el sector militar del PRI y que siempre, en mayor o menor medida, apoyó las propuestas presidenciales pero que, en 1988, apoyó la candidatura a la presidencia del expriista Cuauhtémoc Cárdenas y se adhirió a la coalición de fuerzas políticas progresistas agrupadas del Frente Democrático Nacional. ${ }^{31}$

La participación de estos partidos políticos en los debates parlamentarios fue fundamental debido a que durante la gestión presidencial de Carlos Salinas se logró reformar un total de 55 artículos de la Constitución.

Cuadro 1. Distribución partidaria de los legisladores en la Cámara de Diputados y en la Cámara de Senadores

\begin{tabular}{|c|c|c|c|}
\hline & & Diputados & Senadores \\
\hline \multirow{6}{*}{ 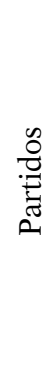 } & PRI & 320 & 61 \\
\hline & PAN & 89 & 1 \\
\hline & PRD & 41 & 2 \\
\hline & PFCRN & 23 & 0 \\
\hline & PARM & 15 & 0 \\
\hline & PPS & 12 & 0 \\
\hline & Total & 500 & 64 \\
\hline
\end{tabular}

En ese momento el PRI tenía una amplia representación tanto en la Cámara de Diputados como en el Senado y sólo requería un mínimo de apoyo. Las leyes reglamentarias sólo requerían de una mayoría simple, es decir, únicamente se exigía el voto de la mitad más uno de los diputados presentes. Para reformar un artículo de la Constitución federal se requiere del voto de 2/3 partes de la Cámara de Diputados compuesta por 500 legisladores. En términos reales se necesitaba la votación favo-

\footnotetext{
${ }^{31}$ Roberto Ortiz Vega, Partidos, candidatos, plataformas y campañas en los partidos minoritarios, Universidad Autónoma Metropolitana, http://dcsh.izt.uam.mx/cen_doc/cede/Anuario_Elecciones_ Partidos_Politicos\%20/1994_div/Partidos\%20minoritarios\%201994.pdf (Consultado el 24-6-2018).
} 
rable de 334 votos a favor y el PRI contaba con 320 legisladores, por lo que sólo requería el apoyo de cuando menos 14 votos. Posteriormente la iniciativa pasó a la Cámara de Senadores, para discutirse en comisiones de trabajo, elaborar un dictamen, debatir en el pleno y finalmente se sometió a votación. La siguiente gráfica muestra la distribución partidaria de los legisladores en la Cámara de Diputados y en la Cámara de Senadores que, hasta ese momento sólo estaba compuesta por 64 congresistas. ${ }^{32}$

Después de concluir las discusiones en ambas cámaras, el proceso legislativo en México establece que se debe enviar y discutir la minuta elaborada a las legislaturas estatales. En el caso de una reforma a la Constitución federal se requiere que la propuesta sea aprobada por lo menos en 16 de los 32 congresos estatales. ${ }^{33}$ El siguiente esquema describe el proceso general que siguieron las dos reformas constitucionales al artículo 3, desde la iniciativa del presidente hasta su entrada en vigor. ${ }^{34}$

En cada una de las etapas del proceso legislativo se realizaron diversas acciones para puntualizar el contenido de la reforma propuesta por el presidente; sin embargo, para efectos de este trabajo se analizan sólo las discusiones en pleno para observar los puntos medulares y los temas específicos relacionados con la educación laica; además de que fueron los únicos lugares donde quedaron registradas las discusiones entre los legisladores.

\footnotetext{
${ }^{32}$ En 1993 se reformó el artículo 56 de la Constitución federal para ampliar el número de senadores a 128 .

${ }^{33}$ Arturo Alemán Sandoval et al., Estudio sobre el proceso legislativo federal en México (México: Instituto Belisario Domínguez/Senado de la República, 2010).

${ }^{34}$ Alejandro Ortiz Cirilo, «La deslaicización educativa: el debate en el Congreso de la Unión y la reforma de 1992» (Trabajo de Fin de Máster, Universidad Autónoma del Estado de Morelos, 2014), 107.
} 


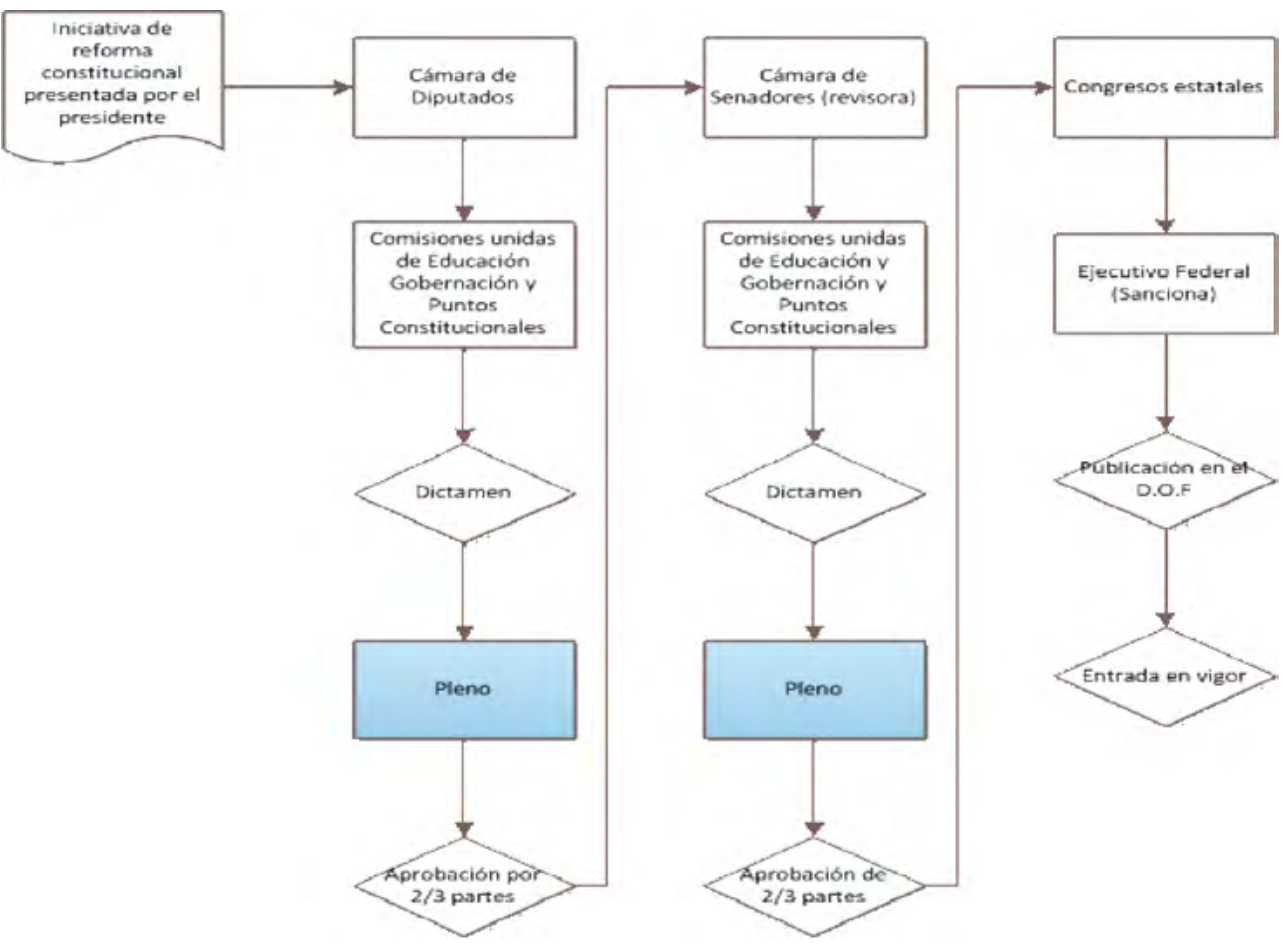

\section{LA INICIATIVA DEL PRESIDENTE}

El 10 de diciembre de 1991 cuando, estaba por concluir el primer periodo ordinario de sesiones, la actividad de la Cámara de Diputados entró en una dinámica de discusiones apresuradas por un paquete de reformas constitucionales, propuestas por el presidente Carlos Salinas, a los artículos que mantenían fuera de los asuntos públicos a la Iglesia católica. El artículo 3, relativo a la educación, impedía la participación del clero en la instrucción primaria y secundaria, así como la destinada a normalistas, obreros y campesinos; el artículo 5 prohibía el establecimiento de órdenes monásticas; el 24 prohibía la manifestación de actos religiosos fuera de los templos; el 27 impedía a las iglesias la adquisición, posesión o administración de bienes raíces; y el 130 no reconocía la personalidad jurídica de las agrupaciones denominadas iglesias y restringía las actividades sociales y políticas de los ministros de culto. En la exposición de motivos que presentó el grupo parlamentario del Partido Revolucionario Institucional (PRI), se retomó la propuesta del pre- 
sidente Salinas bajo los mismos términos y se argumentó que muchas de las normas que integraban el marco constitucional respondieron en su momento a circunstancias históricas que ya no tenían vigencia y que ya habían sido superadas; por lo tanto, era necesario reformar las normas que definían la situación jurídica de las Iglesias y los ministros de culto. ${ }^{35}$

La intención del presidente era que las reformas a la Constitución se aprobaran antes de terminar el periodo ordinario de sesiones. Así, esta legislatura contó con poco más de un mes para el análisis y aprobación de estas propuestas de reforma constitucional y de diversas y complejas leyes; por ejemplo, entre las iniciativas de reforma se encontraban aquellas que modificaban las leyes fiscales para el ejercicio del año siguiente, integrantes de la denominada miscelánea fiscal de $1991 .^{36}$

Estas propuestas despertaron gran interés entre legisladores de distintos partidos políticos y motivaron un fuerte debate en el que se expresaron puntos de vista muy opuestos. Desde su presentación ante el Congreso y la lectura de la exposición de motivos, contando el periodo de receso por el final de año y las discusiones y aprobación en los congresos estatales, hasta su publicación en el Diario Oficial de la Federación, transcurrieron solamente 50 días. La reforma al artículo 3 derogó la fracción IV en la que se señalaba que:

IV. Las corporaciones religiosas, los ministros de los cultos, las sociedades por acciones o sociedades ligadas con la propaganda de cualquier credo religioso no intervendrán de forma alguna en los planteles que se imparta la educación primaria, secundaria y normal destinada a obreros y a campesinos.

En el momento que llegó la iniciativa presidencial al Congreso para reformar el artículo 3, un grupo minoritario de diputados encabezados por Helí Herrera Hernández del PPS, José María Téllez del PFCRN

\footnotetext{
${ }^{35}$ La propuesta de reforma se articuló en seis partes, a saber: 1) La personalidad jurídica de las iglesias; 2) La propiedad; 3) La libertad de culto externo; 4) La educación; 5) La situación jurídica de los ministros de culto y, 6. Disposiciones en materia civil relativas al tema.

${ }^{36}$ Cámara de Diputados, «Iniciativas presentadas en el primer periodo ordinario del primer año de la LV legislatura», Crónica Parlamentaria, Cámara de Diputados. http://cronica.diputados.gob.mx/ Iniciativas/55/dd55_a1primero.html (consultado el 6-10-2017).
} 
y Carlos González Durán del PRD, presentaron una moción suspensiva para detener la discusión de la iniciativa presidencial. ${ }^{37}$ En este sentido calificaban las reformas como hechas al vapor, mediocres, y destacaban la irregularidad del proceso legislativo. Los diputados a favor de la iniciativa presidencial, Nahúm Idelfonso Zorrilla, Jaime Olivares Pedro y Juan Antonio Nemi — todos del PRI- expresaron su apoyo incondicional a la propuesta de reforma constitucional. Este recurso fue desechado en votación económica ${ }^{38}$ por una abrumadora mayoría de legisladores del PRI e inmediatamente se procedió a la discusión en general ante el pleno del Congreso.

Mucho antes de que se presentara la iniciativa y se comenzara a discutir en comisiones de trabajo y en el pleno del Congreso, ya existía una oposición muy clara en contra de la reforma presentada por el presidente Salinas. Pese a las diferencias de alcance institucional y temático, en los debates legislativos encontramos equivalencias en algunos argumentos y en ciertas conclusiones que merecen ser analizadas a la luz de sus escenarios particulares y de la proyección más amplia de las polémicas sobre la mayor o menor aceptación del concepto de educación laica.

\section{LOS PUNTOS MEDULARES DEL DEBATE}

Las discusiones en el pleno en la Cámara de Diputado comenzaron el 17 de diciembre de 1991. En cada intervención de los legisladores surgieron temas subyacentes al problema de la educación laica. Si bien buena parte de los debates centraron su atención en la integración de dicho concepto, también es cierto que hubo tópicos que se refieren a su configuración de manera indirecta; desde luego, al ser un problema muy amplio abarcó distintos aspectos, pero esencialmente los temas debatidos en estas reformas fueron los siguientes:

a) El control de la educación. Los puntos que los legisladores estuvieron discutiendo se centraban en si los padres debieran mantenerse al margen del proyecto educativo y si éste debía aceptarse

\footnotetext{
${ }^{37}$ La moción suspensiva es una proposición que realiza un legislador o un grupo de legisladores durante el desarrollo de una sesión para detener el trámite o discusión algún asunto en el pleno de la Cámara.

${ }^{38}$ Ese proceso consiste esencialmente en solicitar a los legisladores el sentido de su voto levantando la mano o poniéndose en pie sin tener que recurrir al conteo de los votos.
} 
como una imposición estatal, o bien ver la forma de que los padres tuvieran injerencia respecto al tipo de educación que se enseñaría en la escuela pública.

b) Los contenidos educativos. El problema radicaba en determinar lo que se enseñaría en la escuela pública, y sobre todo el control en los programas y contenidos curriculares. La pregunta que los legisladores se hacían constantemente era si debieran estar acorde a los valores religiosos y respecto a si se debía abordar o no la educación sexual en las escuelas.

c) La educación religiosa en la escuela privada resaltó como tema de interés para la mayor parte de los legisladores, ya que al suprimirse la fracción IV del artículo 3 se podría impartir este tipo de educación en centros educativos privados.

Insistentes denuncias prevalecieron en el pleno, como las que realizó la diputada Patricia Ruíz del PRD, quien presentó un voto particular en contra de la iniciativa, por considerar que con ella se iniciaba un debate nacional que atravesaba todas las instituciones de la sociedad, y en el que no existía consenso. Por lo tanto, era «falso, de mala fe y golpista» ${ }^{39}$ aprobar al vapor la iniciativa, sin que hubiera antes una mínima consulta popular. En alusión a ésta y las demás modificaciones a la Constitución que se habían debatido en este periodo legislativo, afirmó que no eran simples reformas, sino "la instauración de una nueva Constitución». De igual forma, la legisladora Ruíz pidió que se realizara un referéndum para consultar sobre las reformas que ahora se proponían y manifestó su voto en contra del dictamen. No obstante, al ser considerados los legisladores como representantes políticos de los ciudadanos mexicanos no se requería un consenso a nivel nacional, y por lo tanto su demanda no tuvo eco en la mayoría de los legisladores. Con la derogación de la fracción IV se anularon las restricciones que frenaban la participación de agentes religiosos en la educación privada. Lo cierto es que desde que se presentó el proyecto de reforma hubo protestas e inconformidades al respecto como no se habían manifestado anteriormente, fue una iniciativa por demás polémica en la que se discutió am-

${ }^{39}$ Cámara de Diputados del H. Congreso de la Unión, Derechos del pueblo mexicano, México a través de sus constituciones (México: Miguel Ángel Porrúa/Cámara de Diputados LVII legislatura, 2000), 667. 
pliamente el tema de las relaciones Estado-Iglesia y, sobre todo, como se vería modificado el artículo 3 para permitir la impartición de enseñanza religiosa en las escuelas privadas. En seguida se explican con más detalle los argumentos en pugna con respecto a cada uno de los ejes centrales de discusión que hemos identificado.

\section{Sobre el control de la educación}

El artículo 3 vigente desde 1946 permitía a los establecimientos particulares impartir educación en cada uno de los niveles educativos; para ello debían obtener una autorización del Estado, pero debía ser laica la que se impartiera en preescolar, primaria, secundaria, formación de maestros y para obreros y campesinos. La autorización conferida por los poderes públicos a los particulares podía ser negada o revocada sin posibilidades de interponer algún recurso. En última instancia era el Estado quien tenía el control sobre todas las actividades educativas, y esto también incluía la orientación y los contenidos que se debían seguir tanto en instituciones educativas públicas como en las escuelas privadas. Por esta medida, la Unión de Padres de Familia sostenía que como las escuelas del Estado y las particulares debían ser laicas, de acuerdo a la legislación, se negaba el derecho de los padres de familia a escoger el tipo de educación para sus hijos acorde a sus convicciones éticas y morales.

Los cambios en la legislación educativa evidencian un nuevo giro respecto a cómo se debía entender la educación laica; no sólo era un cambio de forma sino también de fondo, ya que ahora los cuestionamientos giraban en torno al papel de los padres de familia y de los tutores.

Al mismo tiempo se puede apreciar un desplazamiento del Estado como rector y un fortalecimiento de los particulares para impartir educación en todos sus tipos y modalidades; estos cambios se dieron en dos momentos importantes y con dos reformas constitucionales al artículo 3. El primer cambio importante consistió en la reformulación de la fracción III de este artículo que establecía que:

III. Los particulares podrán impartir educación en todos sus tipos y grados. Pero por lo que concierne a la educación prima- 
ria, secundaria y normal (y a la, de cualquier tipo o grado, destinada a obreros y a campesinos) deberá obtener previamente, en cada caso, la autorización expresa del poder público. Dicha autorización podrá ser negada o revocada, sin que contra tales resoluciones proceda juicio o recurso alguno.

La parte del artículo tercero que se discutió más fue precisamente la que terminaría por ser omitida, permitiendo así que los particulares pudieran apelar o interponer un recurso jurídico en contra de las resoluciones emitidas por las autoridades educativas que afectaran sus labores. El debate legislativo se centró en derogar o no la facultad del Estado para negar o revocar la autorización a los particulares de impartir educación: es decir, ahora los particulares podrían interponer recursos administrativos en contra cualquier disposición de las autoridades educativas. Aún cuando el Estado siguió teniendo control respecto a las disposiciones legales, lo cierto es que ahora los particulares podían interponer recursos administrativos para expresar su inconformidad.

Durante esta misma reforma, también se derogó la fracción V del artículo 3, que establecía la facultad del Estado para retirar discrecionalmente, en cualquier tiempo, el reconocimiento de validez oficial a los estudios hechos en planteles particulares. Como se puede apreciar hay un repliegue de la figura estatal y un mayor fortalecimiento de los particulares en el terreno educativo.

Por otra parte, una de las críticas que más se expresaron en las participaciones ante el pleno del Congreso fue que en ninguna parte del texto del artículo 3 se garantizaba el derecho de los padres de familia o tutores de escoger el tipo de educación para sus hijos de acuerdo a sus convicciones éticas y/o morales; no obstante, habría que preguntarse hasta qué punto este tipo de argumentos representaban realmente a los padres de familia o bien a una fracción disidente de corte religioso católico.

Durante este periodo de debates, la Unión Nacional de Padres de Familia desplegó un comunicado en el que se oponía de manera tajante a las restricciones impuestas en las fracciones IV y V del artículo 3, pues consideraban que estas disposiciones estaban en contra de las actividades educativas en los planteles particulares y estimaban que era una 
medida excluyente, restrictiva y además había un estado de indefensión del individuo que, desde su perspectiva, posibilitaba cualquier tipo de arbitrariedad y de intimidación. ${ }^{40}$

El diputado Jorge Zermeño Infante, del PAN, expresó que la educación tenía especial relevancia por el contenido ideológico y la orientación que a través del tiempo el régimen ha postulado en este ámbito. Aseguró que el PAN seguiría insistiendo para incorporar plenamente a la legislación el derecho preferente de los padres de familia para educar a sus hijos de acuerdo a sus principios y convicciones, lo que en múltiples países es práctica común, como un derecho de los padres en la educación que se imparte por el Estado. Según Zermeño, la razón de esto se encuentra en la naturaleza misma de las personas, en la voluntad de los padres que pretenden transmitir en sus hijos valores morales y culturales que consideran importantes para su desarrollo integral. Respecto a la educación secundaria obligatoria como responsabilidad del Estado y de los padres de familia, tanto en el artículo tercero como en el 31 constitucional, el diputado panista advirtió que este propósito era saludable, en la medida en que se impulsara una mayor participación social, que podía a corto plazo dar cabal cumplimiento a este derecho.

Desde el momento que se presentó al pleno del Congreso el dictamen de reforma al artículo 3, los diputados del PRI se mostraron solidarios y apoyaron cabalmente que las propuestas del presidente fueran aprobadas. El legislador Juan Antonio Nemi, del PRI, planteó que la responsabilidad de su partido era en favor de la modernización de las relaciones entre el Estado-Iglesia. Diputados del PAN como José Francisco Paoli pugnaron por dar paso a la construcción de un tiempo más plural y establecer relaciones más justas del Estado mexicano con la Iglesia católica. ${ }^{41}$

Desde luego, también hubo legisladores de partidos políticos «opositores», pero que en sus participaciones avalaron los cambios a la

\footnotetext{
${ }^{40}$ Unión Nacional de Padres de Familia, Miembro de la Unión Iberoamericana de Padres de Familia, «Análisis de la iniciativa de reformas a los artículos tercero y 31 de la Constitución Política de los Estados Unidos Mexicanos», noviembre de 1992, en Honorable Congreso de la Unión, Información sobre el artículo 3 constitucional, Cuadernos de Apoyo 11.

${ }^{41}$ Cámara de Diputados del H. Congreso de la Unión, Derechos del pueblo mexicano, México a través de sus constituciones (México: Miguel Ángel Porrúa/Cámara de Diputados LVII legislatura, 2000), 625 .
} 
Constitución, como el entonces diputado Francisco Laris del PARM, quien, al hacer referencia a la democracia, la libertad del ser humano y la libertad religiosa, consideró que no había peligro en el hecho de que existiera participación de grupos religiosos y ministros de culto en la educación.

Al tiempo de los debates surgieron desacuerdos entre correligionarios de los partidos opositores sobre todo del PFCRN. Por ejemplo, el diputado Javier Centeno Ávila expresó que: «no tiene nada de modernizador retornar a la educación confesional», y añadió que si se aceptaba la iniciativa del presidente la Iglesia católica buscaría en forma más abierta la hegemonía política. En tanto, Adolfo Kunz, del mismo partido, señaló que de aprobarse la reforma a la educación «habremos alcanzado la consolidación de varias de las más preciadas libertades del hombre [...] sin prejuicios ni rencores, con equidad y conservando la memoria para evitar cometer los mismos errores». ${ }^{42}$ Por ello, y en vista de que el dictamen coincidía con las posiciones del liberalismo social defendidas por el PARM, su partido votaría en favor de la iniciativa.

Desde un punto un tanto diferente, Jorge Tovar Montañez, del Partido Popular Socialista, afirmó que era falso que en México no hubiera libertad educativa para que los padres de familia en su conjunto pudieran educar a sus hijos de acuerdo a sus convicciones éticas y/o morales. Desde esta perspectiva afirmó que:

Los conceptos evolucionan, las ideas evolucionan, cambian y el concepto de laicismo en el que tenemos que insistir, es un concepto de laicismo no neutro, el laicismo que plantean los maestros, algún grupo de maestros del partido oficial en un documento que hicieron público. Un laicismo comprometido, un laicismo que llegue al conocimiento científico, no un laicismo inocuo, neutro. ${ }^{43}$

\footnotetext{
42 Cámara de Diputados del H. Congreso de la Unión, Derechos del pueblo mexicano, México a través de sus constituciones, 649.

${ }_{43}$ Cámara de Diputados del H. Congreso de la Unión, Derechos del pueblo mexicano, México a través de sus constituciones, 797.
} 


\section{Sobre los contenidos educativos}

La fracción III del artículo 3 de la Constitución de 1946 establecía que los particulares debían cumplir con los planes y programas oficiales. Con la reforma al artículo 3 constitucional en 1993, además de establecer la obligatoriedad de la educación secundaria, también se modificó el control de los contenidos educativos; ahora estarían determinados por el ejecutivo federal y éste consideraría la opinión de los gobiernos de las entidades federativas y de los diversos sectores sociales involucrados en la educación.

Los núcleos de las discusiones en el Congreso de la Unión giraban en torno a quien debía fijar los contenidos educativos, bajo qué principios filosóficos debía apoyarse su orientación, y sobre todo en qué niveles educativos. En consecuencia, la iniciativa comprendía incorporar al artículo 3 la facultad del ejecutivo federal para determinar los planes y programas de estudio, que deberían ser observados y aplicados en toda la República, en los ciclos de educación primaria, secundaria y normal. No obstante, como en cualquier debate parlamentario, se presentaron posturas diametralmente opuestas, en este caso en lo relativo a los contenidos en la educación básica y como debían entenderse respecto al carácter laico.

Los debates condujeron a negar la laicidad educativa no sólo en el ámbito de lo privado sino también en el ámbito de las escuelas públicas. La impartición de contenidos educativos obligatorios, tanto para la educación pública como para la privada en toda la educación básica, era percibida entre algunos los legisladores — sobre todo de PAN- como un grave error que minaba los derechos de los padres de familia y tutores a una educación acorde a su orientación moral; por tanto, se denunciaba en tribuna que esto representaba un menoscabo a la libertad de enseñanza.

Pues bien, la fracción I del artículo 3 establecía que la educación debía ser laica, y por tanto también ajena a cualquier doctrina religiosa: aunque los particulares pudieran dedicarse a la labor educativa, esta debía ser laica. De igual forma, los planteles particulares debían cumplir con lo estipulado en la fracción II, la cual refería que la educación mexicana debía orientarse a la formación integral del ser humano en la de- 
mocracia, el nacionalismo y el aprecio a la dignidad e integridad de la persona, pero también acatar los planes y programas oficiales determinados por el ejecutivo federal.

Al considerar que no era del todo claro que tanto los contenidos educativos como los planes y programas debían ser de carácter laico, los diputados del PFCRN, Abundio Ramírez Vázquez, Demetrio Hernández Pérez y Manuel Terrazas, propusieron que se añadieran los siguientes términos:

Para dar pleno cumplimiento de lo dispuesto en el segundo párrafo y en las fracciones I y II, el Ejecutivo Federal determinará los planes y programas de estudio de la educación primaria, secundaria y normal para toda la República; para tales efectos el Ejecutivo Federal considerará la opinión de los gobiernos de las entidades federativas y de los diversos sectores sociales involucrados en la educación, en los términos que la ley señale.

Es perceptible que esta iniciativa de los diputados del PFCRN de reforma constitucional centralizaba aún más la enseñanza; desde luego había algunos matices de considerar la opinión de los gobiernos de las entidades federativas, pero en el último caso la decisión era del ejecutivo federal. Las implicaciones eran que aun los particulares debían sujetarse a lo estipulado en la Fracción I, es decir, mantener una educación de carácter laico. Esa propuesta se quedó en el aire al pasarse a discutir otros problemas.

Posteriormente el debate se centró en derogar o no la obligación de los centros de educación particular de impartir una educación laica. El diputado del PAN José Francisco Paoli Bolio, en consonancia con los planteamientos de su partido expresó que:

Este es un punto central de la discusión. Nosotros proponemos congruencia entre lo que ocurre en la familia y lo que ocurre en la escuela. No por individualidades porque sería atomizar al infinito esta cuestión, pero sí especificándose opciones por las que puedan los padres de familia tener distintas alternativas. La separación de lo que sería la enseñanza en la familia, que Cesáreo nos refería como la enseñanza de la fe, de la religión y 
de las tradiciones, para luego tener una enseñanza que contradice, que rompe con lo que en la familia se estableció, es precisamente uno de los problemas centrales que se han resuelto en naciones modernas y se aplican hoy soluciones para resolverlas en Bélgica, en Canadá y en otros estados, y no solo son paisajes rousseaunianos, son opciones de educación que se han montado en estos países. Si no se establece una suerte de esquizofrenia porque al educando en la familia se le dice una cosa y otra cosa se le apunta en la escuela, este es el problema de incongruencia que pretendemos resolver. ${ }^{44}$

Las discusiones se centraron en las mismas problemáticas cuando la iniciativa presidencial paso a discutirse en la Cámara de Senadores. El senador Porfirio Muñoz Ledo, del PRD, argumentó que las reformas propuestas por el entonces presidente Salinas convertían en letra muerta la obligación impuesta a los particulares de cumplir con los planes y programas oficiales, ya que, al no verse obligados a respetar la obligación de mantener el carácter laico de los mismos, podían impartir educación acorde a sus propios ideales educativos, y en este sentido se creaba una dualidad en el Sistema Educativo Mexicano, ya que por un lado se mantenía la educación laica en la escuela pública y por otro lado se permitía la educación religiosa en los planteles de educación particular.

\section{Sobre la educación religiosa en las escuelas privadas}

Todas las instituciones privadas debían sujetarse a lo establecido por el Estado, de tal forma que la propuesta consistió en que en la enseñanza privada no existiera la obligación de que éste tipo de educación se mantuviera por completo ajena a cualquier doctrina religiosa pudiendo adquirir abiertamente un carácter confesional.

Con la derogación de la fracción IV se dio entrada a la participación de agentes religiosos en la educación privada. El texto educativo no llega a establecer como tal un incentivo para que los actores religiosos

\footnotetext{
${ }^{44}$ Cámara de Diputados del H. Congreso de la Unión, Derechos del pueblo mexicano, México a través de sus constituciones, 964.
} 
puedan brindar, dirigir o incluso apoyar servicios educativos, sino que por la omisión de estas restricciones se entiende que ahora es posible que se imparta educación religiosa en las escuelas privadas. Considerando la magnitud de la reforma propuesta, Hildebrando Gaytán Márquez, del Partido Popular Socialista, señaló que:

Se está rompiendo la estructura del artículo 3. Para dejar que las escuelas particulares puedan impartir educación religiosa, so pretexto de que se amplía la libertad de esas escuelas y más aún de que se concede este tipo de educación que ha exigido la iglesia católica, en este caso esta medida que está haciendo el Partido Revolucionario Institucional, sí otorga libertad, amplía la libertad a las escuelas particulares para que establezcan la religión, pero quienes van a pagar el costo de esta medida son los niños de México, son los jóvenes del país. Se está haciendo una escisión dentro de la sociedad. ${ }^{45}$

Algunas de las acusaciones en tribuna no sólo referían a la complicidad de legisladores del PAN y del PRI para derogar restricciones y candados a la participación religiosa en escuelas privadas, también se denunció que había francas violaciones a la Ley y así lo expresó Juan Campos Vega, del Partido Popular Socialista, quien cuestionaba sí:

¿Ha respetado la jerarquía eclesiástica estos preceptos fundamentales de la Constitución de nuestro país? ¿Los ha cumplido alguna vez? El hecho es que aun con la prohibición expresa de la ley, existen en México infinidad de escuelas particulares donde se imparte educación religiosa en educación elemental secundaria. ${ }^{46}$

De igual forma, se escucharon voces en tribuna que pugnaban por la actualización del marco jurídico mexicano ya que lo consideraban

\footnotetext{
${ }^{45}$ Cámara de Diputados del H. Congreso de la Unión, Derechos del pueblo mexicano, México a través de sus constituciones, 804.

${ }^{46}$ Cámara de Diputados del H. Congreso de la Unión, Derechos del pueblo mexicano, México a través de sus constituciones, 584-585.
} 
como anacrónico; tal es el caso de la participación del diputado Rodolfo Echeverría del PRI quien señaló que:

Lograr la separación entre el Estado y las iglesias, la libertad de conciencia, la tolerancia de cultos y finalmente el predominio del Estado, obligó a veces a la decisión imperativa, a la separación tajante, al desconocimiento de la existencia jurídica de las otras partes del conflicto, a la promulgación de severas restricciones públicas y privadas, a la imposición de límites que fueron en su tiempo tan razonables como necesarios. Sólo que en todo esto estamos hablando de historia. ${ }^{47}$

Desde el punto de vista de Echeverría, hablar de historia sólo tenía que ver con lo sucedido en el pasado y que por lo tanto ya no tenía vigencia. Una fracción considerable de diputados del PRI, entre los que destacan Luis Moreno Bustamante, Jesús Sarabia Ordoñez, Moisés Armenta Vega, Eloy Gómez Pando, Eduardo Cristerna y Benjamín González Roaro, sostuvieron que la educación debía permanecer bajo el control del Estado, y sólo para la educación pública conservar el carácter laico ya que:

El laicismo representa la incorporación a la Constitución de un principio del que no debe de sustraerse a la educación pública en una sociedad de individuos dotados de iguales libertades, en la que se reconoce y promueve la pluralidad filosófica y religiosa. El laicismo en la educación pública privilegia la adquisición del conocimiento por la vía científica, cuestionando la realidad, sin imponer verdades absolutas, buscando siempre las verdades relativas a través de la crítica, exaltando los valores de la tolerancia y de la racionalidad. ${ }^{48}$

A pesar de su apología del laicismo, en realidad los diputados priistas estaban apoyando de una manera acrítica y gregaria la iniciativa del presidente.

\footnotetext{
47 Cámara de Diputados del H. Congreso de la Unión, Derechos del pueblo mexicano, México a través de sus constituciones, 587.

${ }^{48}$ Cámara de Diputados del H. Congreso de la Unión, Derechos del pueblo mexicano, México a través de sus constituciones, 784.
} 


\section{CONSIDERACIONES FINALES}

La reforma del Estado propuesta por el presidente Salinas tuvo como objetivo emprender cambios acordes a los retos que imponía el neoliberalismo económico. Para ello emprendió una serie de ajustes y privatización de empresas estatales. Estos cambios replantearon sus políticas sociales y es claro que el tema de la educación fue clave para afrontar dichos retos. El gobierno salinista respondió a las presiones ejercidas por la Iglesia católica en un contexto de reanudación de las relaciones diplomáticas con El Vaticano, que actuaba en alianza con los grupos empresariales políticamente conservadores. Y a la vez atendía las demandas históricas de la Unión Nacional de Padres de Familia, brazo secular de la propia Iglesia desde 1917, exigiendo la libertad de enseñanza en las escuelas privadas. Pero a la vez, con la apertura de las escuelas a la enseñanza religiosa de varios credos, abrió un nuevo nicho para el fortalecimiento de la inversión empresarial en el sector educativo, en una coyuntura de "adelgazamiento» del Estado, de restricciones presupuestales en la educación, y de cuestionamiento mediático a la calidad de la educación pública. Esto sería más evidente en los años que siguieron a la reforma, que rebasan los límites de este trabajo.

Por lo que respecta al objetivo de este artículo, quedó claro que después de un intenso debate entre legisladores de partidos opuestos, el 28 de enero de 1992 se publicó en el diario oficial la reforma propuesta por el presidente Salinas al artículo 3 de la Constitución Política de los Estados Unidos Mexicanos. Al cabo de un año y en el mismo periodo legislativo, se volvió a publicar, el 5 de marzo de 1993, otra reforma al texto del artículo 3 constitucional relativo la educación. Estos dos acontecimientos marcaron un quiebre en la política educativa mexicana ya que ambas reformas implicaron un paso atrás en el modelo de la educación laica prevaleciente en México desde 1917, vigente para las escuelas públicas y privadas. De hecho, durante todo el sexenio presidencial de Carlos Salinas de Gortari (1988-1994) se reiteraron los argumentos de que era necesario reformar al Estado y actualizar la situación jurídica de las relaciones entre el Estado y la Iglesia; pero no fue hasta el periodo 1991-1994 cuando el ejecutivo federal realizó una serie de propuestas en las que se contemplaba el tema de la educación laica. 
Los cambios más importantes en esta reforma constitucional fueron la derogación de la fracción IV, que prohibía la participación en la educación a corporaciones religiosas, ministros de culto, y sociedades ligadas a la propaganda de cualquier credo religioso; la modificación, en la fracción II, del concepto de sectas por el de religiones; y la eliminación de las restricciones a la educación privada señaladas en las fracciones III y IV de ese artículo, brindándoles condiciones más abiertas, más liberales.

Por lo tanto, el cambio fundamental de esta reforma se centró en suprimir las reglas que impedían la participación de la Iglesia católica en el espacio público, abriéndoles más el campo de la educación escolarizada. Después de las reformas constitucionales al artículo 3 en 1992 y 1993 el Estado siguió teniendo cierto control sobre la educación en las instituciones educativas privadas; no obstante, como se vio, la mayor parte de las restricciones que limitaban la participación de la Iglesia católica y de otras corporaciones religiosas en la educación se dirimieron en el debate legislativo.

En cada uno de los debates parlamentarios que se suscitaron durante la LV legislatura relativos a la educación laica y su especificidad en la historia de México, hubo tres temas centrales sobre los cuales giraron todas las participaciones en tribuna: el control de la educación, la definición de los contenidos educativos y la posibilidad de impartir enseñanza religiosa en las escuelas particulares. Al analizar la composición partidista, tanto en la Cámara de Diputados como en la de Senadores, es posible advertir que durante ese periodo se presentaron las condiciones políticas favorables y era el momento preciso en que las relaciones de poder político, económico y religioso se articularon para llevar a cabo una reforma de tal magnitud, pues de lo contrario no hubiera sido posible lograr el consenso requerido para reformar los artículos 3, 5, 24, 27 y 130 de la Constitución considerados por las facciones partidistas de derecha como anticlericales.

Aun cuando muchos políticos y organizaciones sociales celebraron que el presidente Salinas comenzara a hablar de las Iglesias -ahora en plural- y no de la Iglesia, lo cierto es que, en la práctica, la Iglesia católica fue la más beneficiada y que los pronunciamientos de los grupos religiosos minoritarios ni siquiera se hicieron presentes en las dis- 
cusiones parlamentarias por la reforma educativa. Pareciera a primera vista que la reforma constitucional realizada al artículo 3 no tocaba o alteraba el fundamento laico de la educación, al permanecer todas las instituciones públicas bajo ese régimen; sin embargo, al reestructurar las funciones entre los espacios públicos y privados de la educación y eliminar la fracción IV y parte de la III del artículo educativo, se abrieron las puertas a la enseñanza religiosa, los ministros de culto, los símbolos y el financiamiento de corporaciones religiosas en escuelas privadas, lo que redujo el espacio de laicidad educativa, fenómeno que ha sido identificado en otros trabajos por nosotros como proceso de des-laicización.

El espacio de laicidad educativa es hoy más estrecho que antes de 1993, pero aún puede encogerse o ampliarse nuevamente. Hay clamores de grupos estrechamente ligados a sectores eclesiásticos que pugnan por la inclusión de la enseñanza religiosa $-\mathrm{y}$ de los ministros de culto- en la escuela pública, y por la erradicación de temas como la educación sexual y los derechos derivados de la diferencia de géneros, entre otros contenidos escolares. El embate en contra de la educación laica tiene diversas manifestaciones, y una de las más concretas se ha desplegado en las propuestas de leyes y de reformas a la legislación educativa para permitir la enseñanza religiosa en distintos espacios, incluyendo las escuelas públicas. Un gradual proceso de «deslaicización educativa», que incluyera la enseñanza religiosa y que segmentara a las poblaciones infantiles según sus creencias, podría afectar el aprendizaje de la tolerancia, el respeto a la diversidad, las prácticas democráticas, la formación ciudadana, la consolidación de espacios públicos plurales y obstaculizar el acceso a una educación integral. Por nuestra parte, consideramos que el debate sobre los regímenes de laicidad debe continuar, y seguirse discutiendo y argumentando en torno a la potencialidad de espacios de laicidad en todas las instituciones de educación formal como espacios plurales de convivencia, de formación en el respeto a la otredad, de reconocimiento al derecho a pensar diferente, a la diversidad de opiniones y creencias religiosas o la ausencia de tales creencias. 


\section{Notas sobre los autores}

Adelina ArRedondo es doctora en ciencias sociales, investigadora del Instituto de Ciencias de la Educación de la Universidad Autónoma del Estado de Morelos. Pertenece al Sistema Nacional de Investigadores. Ha sido miembro de los Comités Ejecutivos de International Standing Conference of History of Education (ISCHE), del Consejo Mexicano de Investigación Educativa y de la Sociedad Mexicana de Historia de la Educación. Coordinó el grupo internacional «Gender and education». Actualmente coordina el Grupo Permanente Internacional, "Historia de la educación laica», asociado a ISCHE. Ha colaborado en la Universidad Nacional Autónoma de México, la Universidad Autónoma del Estado de Chihuahua, la Universidad Pedagógica Nacional, la Universidad de Toronto, la Universidad de Windsor, la Universidad de Valencia, el Instituto de Nacional de Investigaciones Pedagógicas de Francia (INRP), la Universidad de Lille, la Universidad de la Picardie, la Universidad de Estambul, entre otras instituciones. Ha conducido un centenar de cursos de licenciatura, seminarios de posgrado, dirigido 36 tesis de licenciatura, maestría y doctorado. Ha presentado conferencias magistrales y numerosas ponencias en congresos y otros foros académicos, publicado más de ochenta artículos y capítulos de libros y ocho libros sobre temas relacionados con historia de la educación, formación docente, las políticas y los sistemas educativos y sobre educación laica.

Alejandro Ortiz Cirilo es doctor en educación y Maestro en Investigación Educativa por la Universidad Autónoma del Estado de Morelos. Es autor del libro Laicidad y reformas educativas en México (1917-1992), publicado por el Instituto de Investigaciones Jurídicas de la UNAM. Fue reconocido como investigador visitante de la Biblioteca Nacional de Maestros en Buenos Aires, Argentina. Ha sido asistente de investigación en el Centro de Estudios Sociológicos (CES) de El Colegio de México (COLMEX), y ha presentado diversos trabajos en eventos académicos en México y en el extranjero, relacionados con el tema de la educación laica en México y América Latina. 


\section{REFERENCIAS}

Alemán Sandoval, Arturo et al. Estudio sobre el proceso legislativo federal en México. México: Instituto Belisario Domínguez/Senado de la República, 2010.

Arredondo, Adelina. «De la educación religiosa a la educación laica en el currículum oficial de instrucción primaria en México (1821-1917)». Espacio, Tiempo y Educación 4, no. 2 (2017): 1-x. doi: http://dx.doi.org/10.14516/ ete. 192

Arredondo, Adelina y Roberto González. «De la secularización a la laicidad educativa en México». Historia de la Educación. Anuario. Pulicación de la Sociedad Argentina de Historia de la Educación 15, 2. (2014): 140-167.

Bremauntz, Alberto. La educación socialista en México (antecedentes y fundamento de la reforma de 1934). México: Rivadeneira, 1943.

Cadena-Roa, Jorge y Miguel Armando López Leyva (comps.). El PRD: orígenes, itinerarios, retos. México: Universidad Nacional Autónoma de México/Instituto de Investigaciones Sociales/Centro de investigaciones Interdisciplinarias en Ciencias y Humanidades, 2013.

Castro, Pedro. Las políticas salinistas: balance a mitad de sexenio (1988-1991). México: Universidad Autónoma Metropolitana, Unidad Iztapalapa, 1993.

Delhumeau, Antonio. México: realidad politica de sus partidos. México: Instituto Mexicano de Estudios Políticos A.C., 1977.

Elizondo Mayer-Serra, Carlos. «El Estado mexicano después de su reforma». Política y gobierno II, no. 1 (1995): 95-113.

Fazio, Carlos. Samuel Ruíz. El caminante. México: Espasa Calpe, 1994.

González, Roberto, Lucía Rivera y Marcelino Guerra. Anatomía política de la reforma educativa. México: UPN, 2017.

González, Roberto y Adelina Arredondo. «1861: la emergencia de la educación laica en México». Historia Caribe XII, no. 30 (2017): 25-49.

Islas y Bustamante, Nicolás. Colección de Leyes, Decretos, Reglamentos y Disposiciones sobre Instrucción Pública Vigentes en el Distrito Federal y Territorios de Tepic y Baja California. México: El libro diario, 1893.

Jablonska, Alejandra. «Modernización educativa y ética de la productividad: ejes del nuevo modelo de desarrollo». Revista Mexicana de Ciencias Políticas y Sociales 39, no. 157 (1994): 91-111.

Loaeza, Soledad. El Partido Acción Nacional: la larga marcha, 1939-1994 oposición leal y partido de protesta. México: Fondo de Cultura Económica, 1999.

Loyo, Aurora (coord.). Los actores sociales y la educación: los sentidos del cambio (1988-1994). México: Instituto de Investigaciones Sociales/Plaza y Valdés Editores, 1997. 
Ortiz Cirilo, Alejandro. «La deslaicización educativa: el debate en el Congreso de la Unión y la reforma de 1992». Máster diss., Universidad Autónoma del Estado de Morelos, 2014.

Pérez Méndez, Marco Aurelio. «La Unión Nacional de Padres de Familia y la oposición a la política educativa del Estado revolucionario: 1917-1940». En Representaciones y prácticas sociales. Visiones desde la historia moderna y contemporánea, editado por Rodrigo Laguarda (Coord.), 131-165. México: Instituto Mora, 2013.

Salinas de Gortari, Carlos. Diálogo Nacional. Revista de la consulta popular, Educación. México: Partido Revolucionario Institucional, Instituto de Estudios Políticos, Económicos y Sociales, 1987.

Sánchez Medal, Ramón. La presencia de Juan Pablo II en México y las relaciones Iglesia-Estado. México: Grupo Promoval, 1992.

Staples, Anne. Educar: panacea del México independiente. México: Ediciones el caballito, 1985.

Torres Septién, Valentina. La educación privada en México 1903-1976. México: El Colegio de México/Universidad Iberoamericana, 1997.

Vázquez, Josefina Zoraida. «La modernización educativa (1988-1994)». Historia Mexicana XLVI, no. 4 (1996): 927-952. 